\title{
PENGARUH KOSENTRASI SARI BUAH MANGGA KUWINI TERHADAP KUALITAS PERMEN KERAS
}

\author{
EFFECT OF KUWINI FRUIT EXTRACT CONCENTRATION \\ ON HARD CANDY QUALITY
}

\author{
Sjamsiwarni Reny Sjarif \\ Balai Riset dan Standardisasi Industri Manado \\ Jalan Diponegoro No. 21-23 Manado \\ Telp. (0431) 852395, Fax. (0431) 852396 \\ Pos-el: Reny sjarif@yahoo.co.id
}

\begin{abstract}
ABSTRAK
Mangga kuwini (Mangifera odorata Griff.) tergolong anggota genus Mangifera. Buah tersebut mempunyai aroma yang khas setelah masak, dapat dipergunakan untuk memberikan rasa dan aroma pada makanan. Penelitian ini bertujuan untuk mengetahui pengaruh penambahan sari buah mangga kuwini terhadap kualitas permen keras. Penelitian dilaksanakan dalam beberapa tahap yaitu: pembuatan sari buah, pembuatan permen dan pengujian mutu permen. Metode yang digunakan adalah metode percobaan secara Rancangan Acak Lengkap, dua kali ulangan dengan dengan perlakuan penambahan sari buah mangga kuwini [M $(0,20,25,30,35 \%)]$. Hasil penelitian menunjukkan bahwa perlakuan penambahan sari buah mangga kuwini terhadap nilai rata-rata kadar air berkisar antara 0,83-1,94\%, kadar sukrosa 70,3-75,09\%, kadar gula reduksi 11,06-12,51\% dan kadar vitamin C berkisar antara 0-1,52 mg/g. Penambahan sari buah mangga kuwini pada permen berpengaruh nyata terhadap kadar air, gula reduksi, kadar vitamin $\mathrm{C}$, warna, bau dan tidak perpengaruh nyata pada kadar sukrosa, tekstur dan rasa permen. Permen keras dengan penambahan sari sari buah mangga kuwini memenuhi syarat mutu SNI 3547.1:2008 untuk parameter kadar air, kadar sukrosa, kadar gula reduksi, kadar abu, dan secara organoleptik disukai panelis.
\end{abstract}

Kata kunci: Kuwini, mangga, permen

ABSTRACT

Kuwini (Mangifera odorata Griff.) belongs to the Mangifera genus. The fruit has a distinctive aroma when ripe and can be used as food it can be flavor and flavour. This study aims to determine the effect of kuwini juice an addition to the quality of hard candy. The research was carried out in several stages, namely: fruit juice making, candy making and candy quality testing. This research used random design experiment as the method, two replications with addition treatment of kuwini mango juice [M $(0,20,25,30$, $35 \%)]$. The results showed that the treatment of adding kuwini mango juice to the average value of water content ranged from 0.83 to $1.94 \%$, sucrose levels 70.3 to $75.09 \%$, reduction sugar levels $11.06-12.51 \%$ and vitamin $C$ levels range from $0-1.52 \mathrm{mg} / \mathrm{g}$. The addition of kuwini mango juice to candy significantly affected the water content, reducing sugar, vitamin $C$ levels, color, odor and did not significantly affect the sucrose content, texture and taste of candy. Hard candy with the addition of kuwini mango juice meets the quality requirements of SNI 3547.1:2008 for parameters of moisture content, saccharose content, reducing sugar content, ash content, and organoleptically preferred by panelists

Keywords: Candy, kuwini, mango.

\section{PENDAHULUAN}

Permen merupakan produk pangan yang banyak digemari masyarakat. Salah satu jenis permen yang banyak beredar adalah hard candy (permen keras). Permen keras merupakan salah satu permen nonkristalin yang dimasak dengan suhu tinggi $\left(140-150^{\circ} \mathrm{C}\right)$ yang memiliki tekstur keras, penampakan mengkilat, dan bening. Bahan utama dalam pembuatan permen jenis ini adalah sukrosa, air, sirup glukosa atau gula inversi. Sedangkan bahan-bahan lainnya adalah perasa, pewarna, dan zat pengasam $^{(1)}$.

Kuwini (Mangifera odorata Griff.) tergolong anggota genus Mangifera. Buah tersebut mempunyai aroma yang khas setelah masak. Kuwini dapat dibedakan dari jenis mangga lainnya dari bentuk dan aromanya. Daging buah kuwini lunak berair 
berwarna kuning serta berserabut kasar sedangkan rasa buahnya manis asam. Komponen senyawa flavor pada kuwini terdiri dari $45 \%$ monoterpen teroksigenasi dan $33 \%$ ester dengan $\alpha$-terpineol sebagai komponen utamanya. Kuwini aromanya yang unik dapat dipergunakan juga untuk memberikan rasa dan aroma pada makanan. Sari buah mangga kuwini mengandung kadar air 81,0 $\%$, kadar gula 14,8 \% dan kandungan vitamin C $27,7 \mathrm{mg} / \mathrm{g}^{(2)}$.

Menurut Prissilia $^{(3)}$, kuwini merupakan sejenis mangga yang memiliki nilai jual rendah pada saat panen raya. Salah satu upaya untuk menaikkan nilai jual kuwini adalah dengan mengolah mangga kuwini menjadi produk sehingga umur simpannya dapat meningkat. Mangga kuwini merupakan buah yang cukup digemari oleh masyarakat karena rasa kombinasi yang manis dan asam, memiliki aroma yang khas mirip dengan buah bacang, tetapi buah kuwini memiliki umur simpan yang rendah, karena bersifat mudah busuk karena kadar air yang cukup tinggi. Jumlahnya yang banyak atau berlebih saat musim panen juga menjadi kerugian bagi petani karena nilai jualnya tidak terserap oleh pasar dan juga bersifat musiman, sehingga dilakukan pengolahan produk agar buah tersebut dapat bersaing di pasaran luas dan dapat ditingkatkan nilai ekonominya. Formulasi dalam pembuatan permen sangat penting dan sangat menentukan karakteristik produk. Penambahan sari buah mangga kuwini diharapkan dapat menggantikan bahan tambahan pangan untuk perasa pada permen keras dengan memberikan nilai tambah terhadap buah mangga kuwini. Penelitian ini bertujuan untuk mendapatkan permen keras dari sari buah mangga kuwini dan disukai panelis.

\section{BAHAN DAN METODE}

Bahan utama yang digunakan dalam pembuatan permen adalah buah mangga kuwini yang diambil sarinya dengan tingkat kematangan fisiologis, glukosa, gula pasir, asam sitrat, serta bahan-bahan kimia lainnya. Peralatan yang digunakan dalam penelitian ini adalah, cetakan permen, sendok kayu, pisau, blender/juicer extractor (multi function food processor), kain saring, talenan, wajan, hot plate, panci, loyang plastik, timbangan, gelas ukur, termometer, dan peralatan untuk analisis laboratorium.

\section{Metode Penelitian}

Penelitian ini dilaksanakan dalam beberapa tahap yaitu:

\section{Pembuatan ekstrak sari buah mangga kuwini}

Buah disortasi dan dicuci dengan air bersih. Kemudian kulit buah dikupas, buah dipotong-potong dan dihancurkan menggunakan blender/juicer extractor. Kemudian bubur buah disaring dengan menggunakan kain saring, setelah itu diuapkan selama 15 menit untuk mendapatkan sari buahnya.

\section{Pembuatan permen}

Pembuatan permen dilakukan menggunakan metode percobaan yang disusun dalam Rancangan Acak Lengkap dengan 2 kali ulangan. Perbandingan jumlah

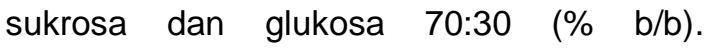
Perlakuan yang digunakan yaitu konsentrasi penambahan sari buah mangga $0 \%, 20 \%$, $25 \%, 30 \%, 35 \%$, menggunakan suhu $150^{\circ} \mathrm{C}$ selama 10 menit. Setelah itu dituang dalam cetakan permen dan didinginkan setelah 
mengeras kemudian dilepaskan dari cetakan dan dikemas.

\section{Pengujian Mutu Permen}

Pengujian mutu permen sesuai $\mathrm{SNI}$ 3547.1:2008 Kembang gula keras ${ }^{(4)}$ yaitu kadar air (metode oven), sukrosa (metode luff schoor), gula reduksi (metode luff schoor), kadar abu (metode gravimetri), kadar vitamin C (metode titrimetri). Uji organoleptik (skala hedonik) yaitu skala 1-5 dimana 5 (sangat suka), 4 (suka), 3 (agak suka), 2 (tidak suka), 1 (sangat tidak suka).

\section{Analisis Data}

Data yang diperoleh dianalisis menggunakan analisis varians dan dilanjutkan dengan uji beda nyata terkecil apabila ada pengaruh perlakuan terhadap parameter yang diukur.

\section{HASIL DAN PEMBAHASAN}

\section{Kadar Air}

Kadar air merupakan jumlah air yang terkandung dalam bahan pangan. Kadar air merupakan karakteristik yang sangat penting karena dapat mempengaruhi penampakan, tekstur, dan cita rasa ${ }^{(5)}$.

Nilai rata-rata kadar air permen dengan penambahan sari buah mangga kuwini berkisar antara 0,83-1,94\%.

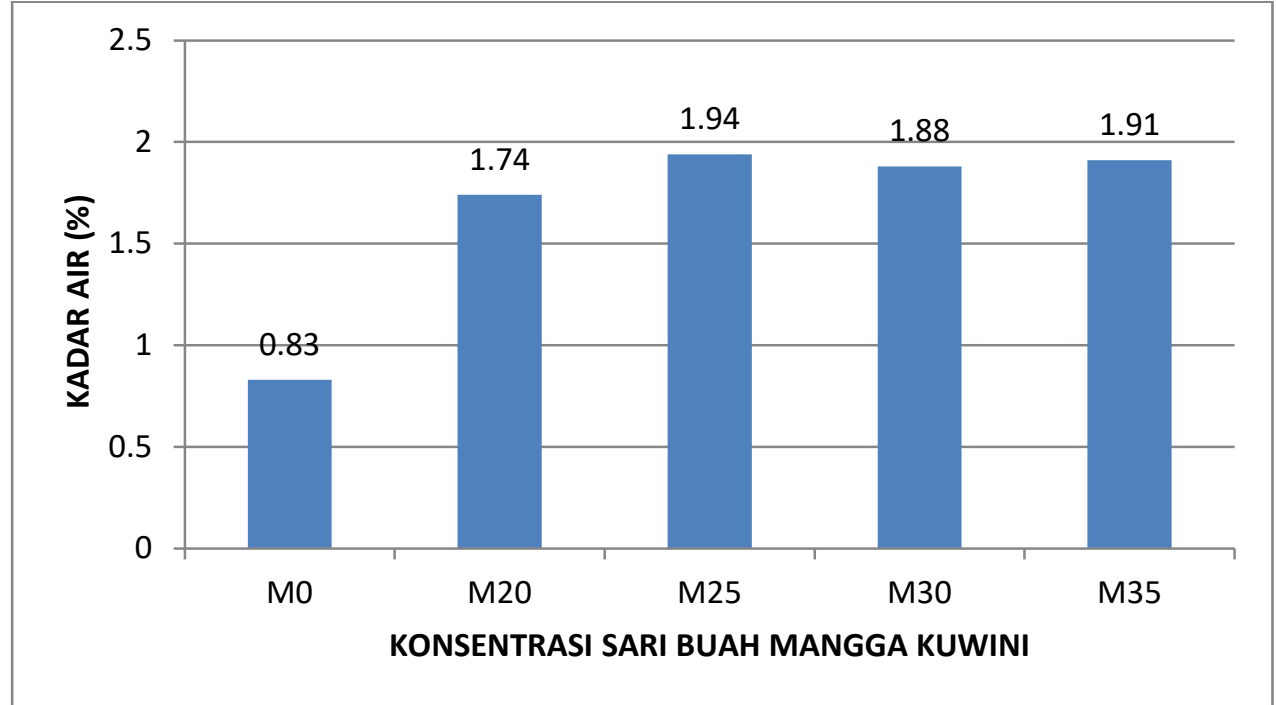

Gambar 1. Histogram perubahan kadar air permen pada proses pembuatan permen mangga kuwini

Hasil analisis varians menunjukkan bahwa perlakuan penambahan sari buah mangga kuwini memberikan pengaruh yang sangat nyata terhadap kadar air permen.

Kadar air dari permen pada perlakuan tanpa penambahan sari buah mangga kuwini yaitu sebesar 0,83\% sedangkan kadar air tertinggi pada perlakuan penambahan sari buah mangga kuwini 25\% (M25) sebesar $1,94 \%$. Terjadinya perbedaan kadar air ini dipengaruhi oleh tingkat inversi sukrosa, dengan penambahan sari buah mangga kuwini. Semua perlakuan penambahan sari buah mangga kuwini yang digunakan menghasilkan permen dengan kadar air yang memenuhi syarat mutu kembang gula keras SNI 3547.1:2008 ${ }^{(4)}$ yaitu maksimal 3,5\%.

Kadar air sangat berpengaruh terhadap mutu dari permen, karena tingkat keawetan permen mempunyai hubungan 
yang erat dengan kadar air yang dikandungnya. Semakin tinggi kandungan sukrosa dari permen, kadar airnya semakin rendah $^{(6)}$.

\section{Kadar Sukrosa}

Sukrosa merupakan polimer dari molekul glukosa dan fruktosa melalui ikatan glikosidik yang mempunyai peranan yang penting dalam pengolahan makanan. Oligosakarida ini banyak terdapat pada tebu, bit, siwalan dan kelapa kopyor. Biasanya gula ini digunakan dalam bentuk kristal halus atau kasar ${ }^{(7)}$.

\section{Dalam} pembuatan

permen perbandingan antara sukrosa dan glukosa, atau antara sukrosa dan gula invert sebagai pengganti sirup glukosa perlu diperhatikan karena kesalahan rasio akan dapat menyebabkan graining/kristalisasi dan juga sticking/ lengket ${ }^{(8)}$.

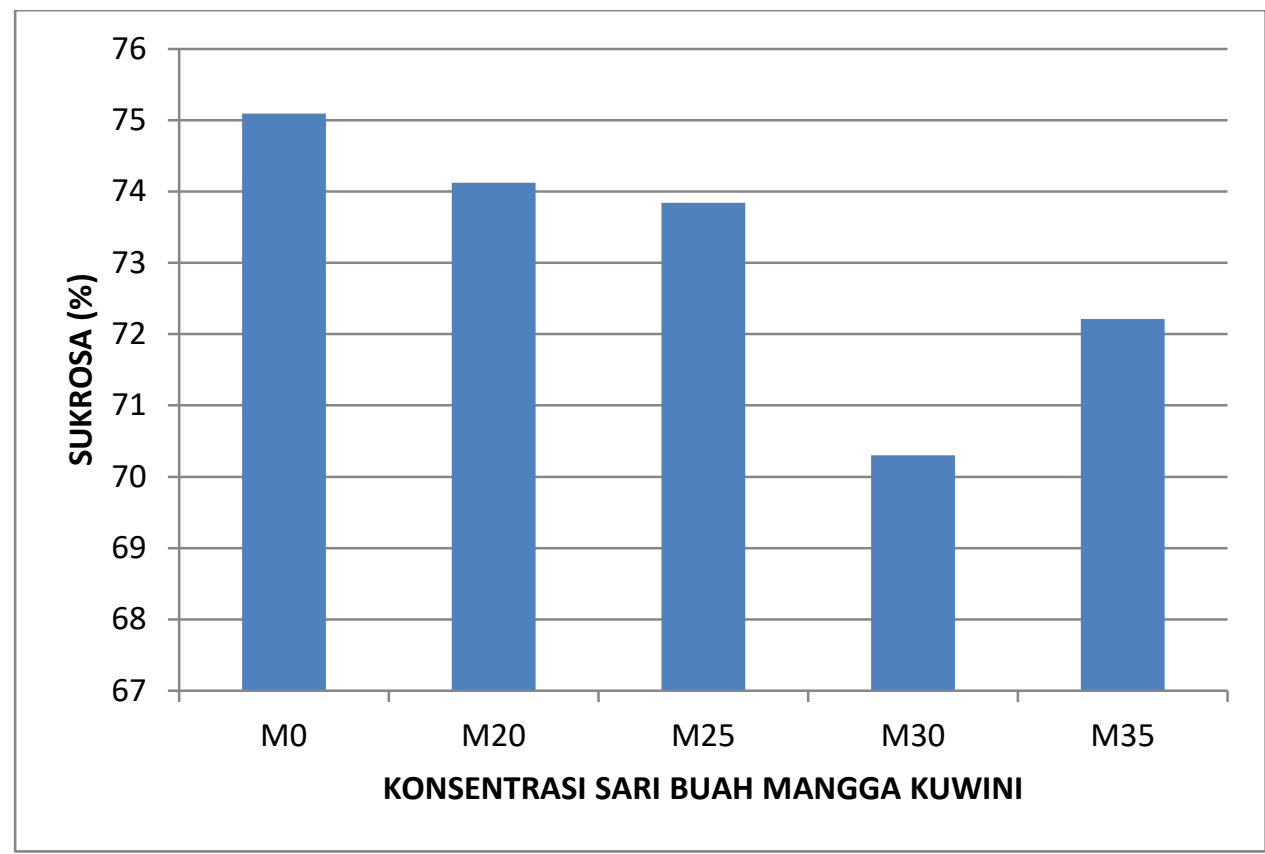

Gambar 2. Histogram perubahan kadar sukrosa pada proses pembuatan permen mangga kuwini

Nilai rata-rata sukrosa permen dengan perlakuan penambahan sari buah mangga kuwini berkisar 70,3-75,09\%. Kadar sukrosa tertinggi terdapat pada perlakuan M0 yaitu $75,09 \%$ dengan tidak menambahkan sari buah mangga kuwini. Kadar sukrosa terendah terdapat pada perlakuan penambahan sari buah mangga kuwini 30\% (M30) yaitu 70,3\%. Hasil penelitian kadar gula dari sari buah mangga kuwini yaitu $14,8 \%$. Penambahan sari buah mangga kuwini tidak mempengaruhi secara nyata terhadap kadar sukrosa.
Sukrosa digunakan dalam pembuatan permen keras umumnya sebanyak $50-70 \%$ dari berat total. Hasil penelitian Wahyuni, $1998^{(6)}$ menunjukkan bahwa peningkatan kadar sukrosa akan meningkatkan kekentalannya agar dihasilkan permen dengan kejernihan yang baik atau penampakan mirip air dibutuhkan gula dengan tingkat kemurnian yang tinggi dan rendah kandungan abunya. Permen yang menggunakan sukrosa murni mudah mengalami kristalisasi, oleh karena itu perlu digunakan bahan lain untuk menghambat 
kristalisasi misalnya sirup glukosa sirup maltosa, dekstrosa, gula invert atau high fructose syrup.

Semua perlakuan penambahan sari buah mangga kuwini menghasilkan permen dengan kadar sukrosa memenuhi syarat mutu kembang gula keras SNI 3547.1:2008 ${ }^{(4)}$ yaitu minimal $38 \%$.

Sukrosa (gula pasir) merupakan senyawa kimia yang termasuk golongan karbohidrat, memiliki rasa manis, berwarna putih, bersifat anhydrous dan larut dalam air. Sukrosa adalah komponen utama permen yang berguna selain sebagai pemanis, juga sebagai sumber padatan ${ }^{(9)}$. Penambahan gula pada produk bukan saja untuk menghasilkan rasa manis, tetapi untuk menyempurnakan rasa asam, citarasa, dan juga memberikan kekentalan. Daya larut yang tinggi dari gula, memiliki kemampuan mengurangi kelembaban relatif $(E R H)$ dan daya mengikat air adalah sifat-sifat yang menyebabkan gula dipakai dalam pengawetan pangan ${ }^{(10)}$.

\section{Kadar Gula Reduksi}

Gula reduksi yaitu gula yang mempunyai kemampuan untuk mereduksi, karena adanya gugus aldehid atau keton. Gula yang termasuk gula reduksi yaitu glukosa, fruktosa, manosa, laktosa, maltosa dan lain-lain. Gula yang termasuk non reduksi adalah sukrosa ${ }^{(11)}$.

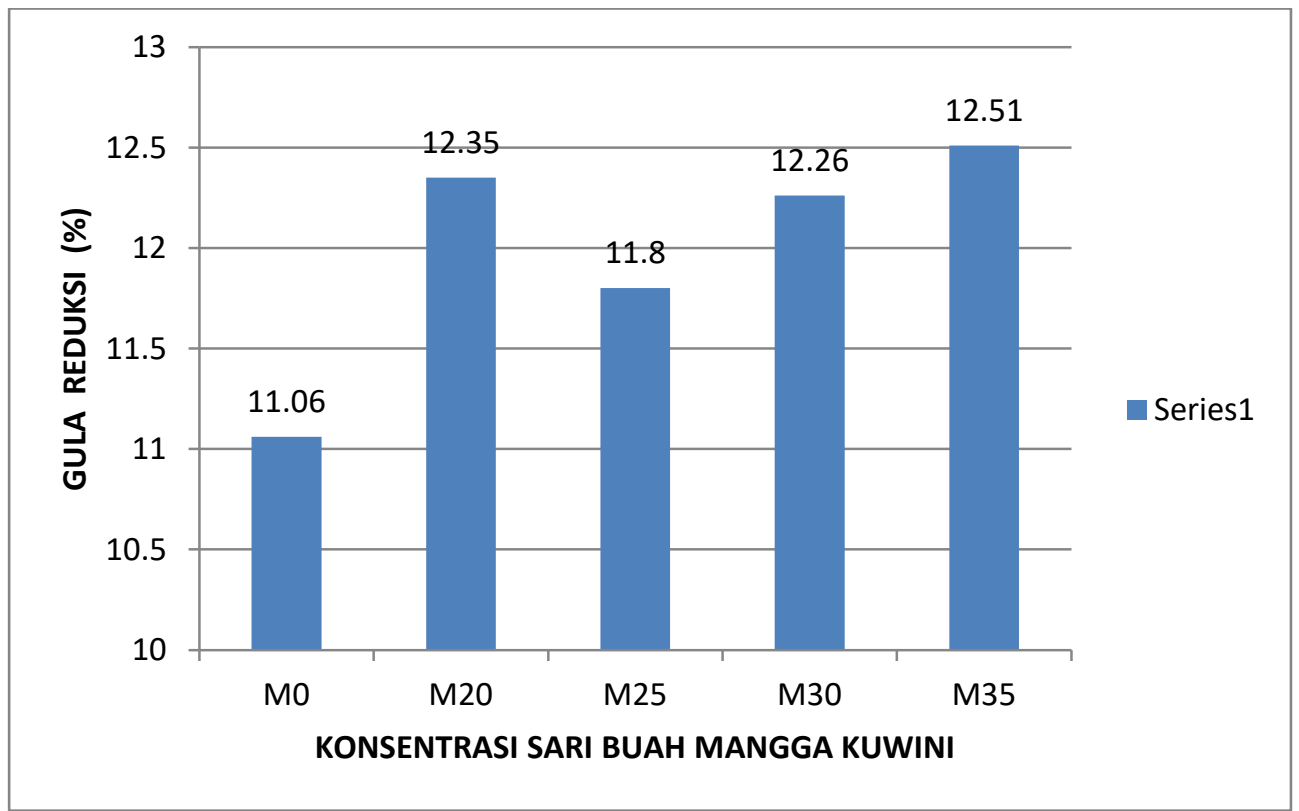

Gambar 3. Histogram perubahan kadar gula reduksi pada proses pembuatan permen mangga kuwini.

Nilai rata-rata gula reduksi dari permen dengan perlakuan penambahan sari buah mangga kuwini berkisar 11,06-12,51\%. Setelah dilakukan analisis varian perlakuan penambahan sari buah mangga kuwini memberikan pengaruh yang sangat berbeda terhadap gula reduksi dari permen. Pada
Gambar 3 dapat dilihat bahwa dengan perlakuan penambahan sari buah mangga dengan konsentrasi yang lebih banyak kadar gula pereduksi makin tinggi. Gula reduksi merupakan salah satu parameter penentu mutu dari permen keras. Gula pereduksi terbentuk karena proses inversi sukrosa 
yang merubah sukrosa menjadi glukosa dan fruktosa, atau campuran keduanya (gula invert) karena pengaruh asam dari sari buah mangga kuwini. Proses inversi sukrosa dipengaruhi oleh beberapa faktor, yaitu suhu pemanasan, lama pemanasan dan konsentrasi asam yang digunakan ${ }^{(12)}$.

Perlakuan penambahan sari buah mangga kuwini yang digunakan menghasilkan permen dengan kadar gula reduksi memenuhi syarat mutu kembang gula keras SNI 3547.1:2008 ${ }^{(4)}$ yaitu maksimal $24 \%$.

\section{Kadar Vitamin C}

Vitamin C merupakan senyawa yang sangat mudah larut dalam air mempunyai sifat asam dan sifat pereduksi yang kuat.
Vitamin C dapat berbentuk sebagai asam askorbat. Asam dalam permen keras selain sebagai gizi juga dibutuhkan untuk membantu pembentukan gula pereduksi. Peran vitamin $C$ dalam tubuh adalah untuk membantu proses penyembuhan luka serta daya tahan tubuh terhadap infeksi.

Kadar vitamin C pada permen keras hasil penelitian dengan penambahan sari buah mangga kuwini berkisar antara 0-1,52 $\mathrm{mg} / \mathrm{g}$. Rendahnya vitamin $\mathrm{C}$ hasil penelitian yaitu pada proses penyiapan sari buah yang digunakan sebagai bahan tambahan pada permen yaitu melalui tahap-tahap pengirisan, penghancuran, pemanasan sehingga vitamin $C$ banyak yang hilang.

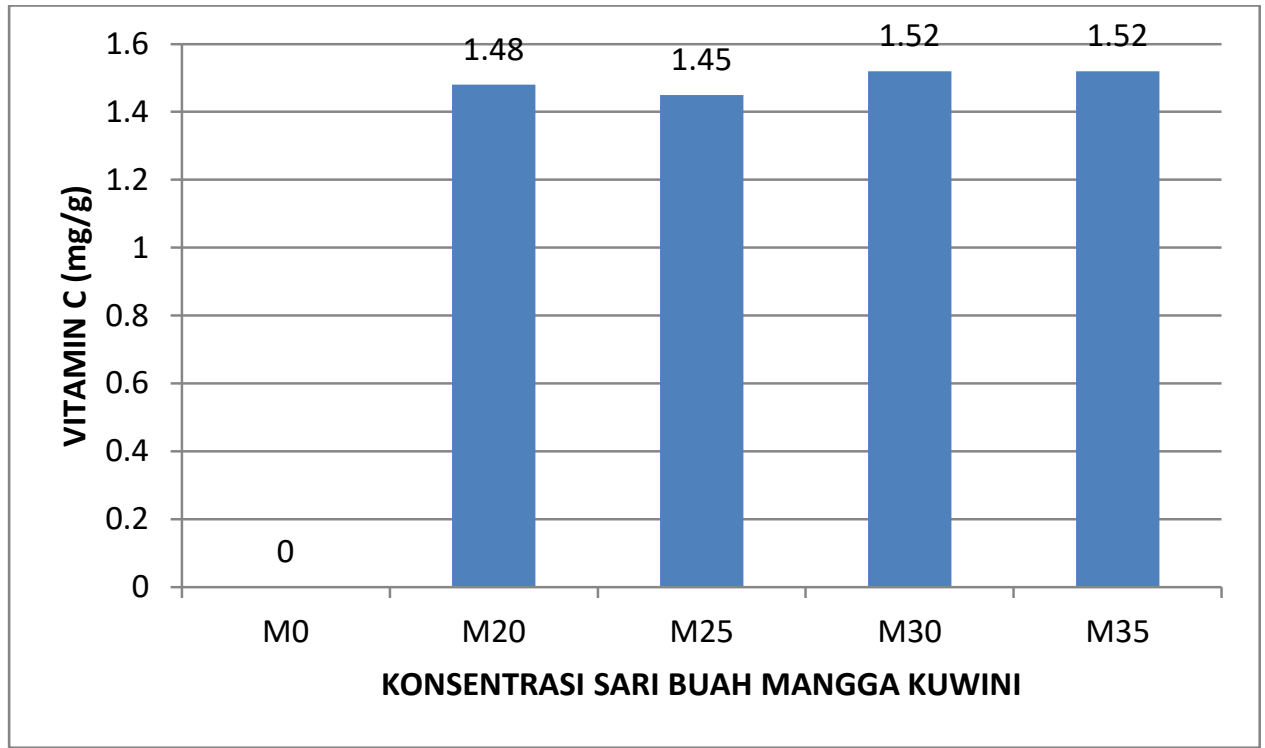

Gambar 4. Histogram perubahan vitamin $\mathrm{C}$ pada proses pembuatan permen mangga kuwini.

Vitamin C mudah larut dalam air dan mudah rusak oleh proses oksidasi, panas, dan alkali. Oleh karena itu agar vitamin C tidak banyak yang hilang, seharusnya penghancuran buah-buahan yang berlebihan dihindari.

Vitamin $C$ adalah vitamin yang paling tidak stabil dari semua vitamin dan mudah rusak selama pemrosesan dan penyimpanan ${ }^{(13)}$.

\section{Kadar Abu}

Kadar abu merupakan zat anorganik sisa hasil pembakaran suatu bahan organik $^{(14)}$. Kadar abu adalah salah satu syarat mutu permen keras karena dengan semakin rendah kandungan abu dalam 
permen, maka penampakan dari permen akan semakin baik. Salah satu bahan baku permen yang berpengaruh terhadap kadar abu dari permen adalah gula pasir atau sukrosa. Gula dengan tingkat kemurnian tinggi dan rendah kadar abunya akan menghasilkan permen dengan kejernihan yang baik atau penampakan mirip air ${ }^{(15)}$.

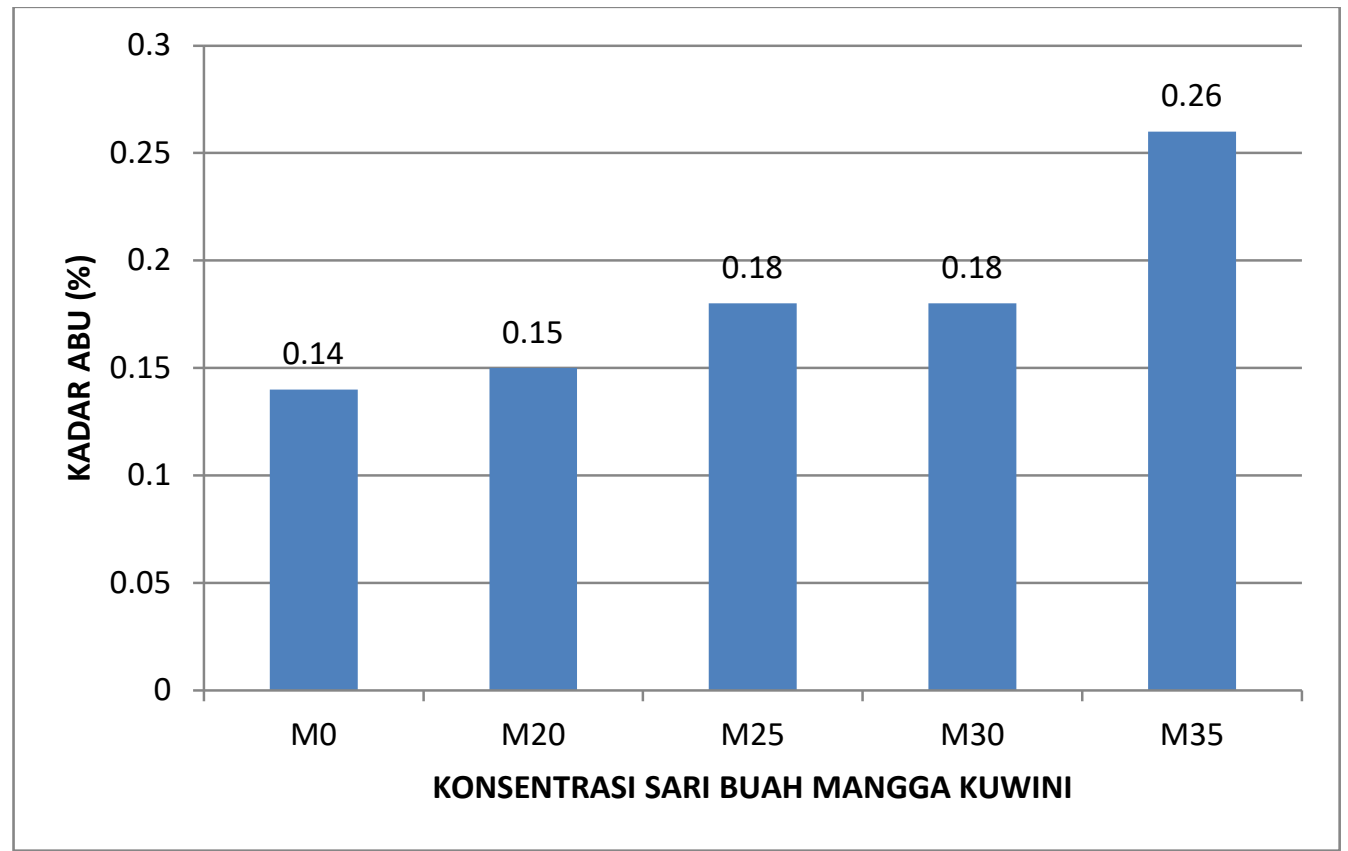

Gambar 5. Histogram perubahan kadar abu pada proses pembuatan permen mangga kuwini.

Hasil analisis kadar abu dapat dilihat pada Gambar 5. Rata-rata nilai kadar abu permen berkisar 0,14 sampai 0,26\%. Berdasarkan syarat mutu kembang gula keras SNI 3547.1:2008 kadar abu tidak boleh lebih dari $2 \%$. Sedangkan kadar abu hasil penelitian yaitu $0,26 \%$.

Menurut Benhard dalam Heni D. Wahyuni $^{(16)}$ gula dengan tingkat kemurnian tinggi dan rendah kandungan abunya akan menghasilkan permen dengan kejernihan yang baik atau penampakan mirip air. Kandungan abu yang tinggi menyebabkan peningkatan inversi pewarnaan dan pembusaan selama pemasakan sehingga memperbanyak gelembung udara yang terperangkap dalam masa gula.

Penentuan kadar abu total dimaksudkan untuk menentukan baik tidaknya suatu proses pengolahan; untuk mengetahui jenis bahan yang digunakan dan penentuan abu total berguna sebagai parameter nilai gizi bahan makanan ${ }^{(17)}$.

\section{Pengujian Uji Organoleptik}

Uji organoleptik dilakukan untuk mengetahui penilaian terhadap produk yang dihasilkan. Jenis pengujian yang dilakukan dalam uji organoleptik ini adalah metode tingkat kesukaan panelis terhadap warna, bau/aroma, tekstur dan rasa yang dihasilkan dari masing-masing perlakuan.

Hasil pengujian organoleptik menunjukkan bahwa nilai rata-rata tingkat kesukaan panelis terhadap warna, bau, tekstur dan rasa permen mangga kuwini berkisar antara 3,45-4,7 (cukup suka-suka). Hampir semua panelis menyukai rasa permen dengan penambahan sari buah 
mangga kuwini. Rata-rata penilaian terhadap tingkat kesukaan warna permen pada penambahan sari buah mangga berkisar $3,54^{\mathrm{a}}-4,7^{\mathrm{c}}$. Hasil analisis varians perlakuan penambahan sari buah mangga memberikan perbedaan nyata pada tingkat kesukaan warna permen yang ditambahkan sari buah mangga. Tingkat kesukaan semakin menurun dengan perlakuan semakin banyak penambahan sari buah mangga pada permen. Semakin banyak penambahan sari buah pada permen, warna permen yang dihasilkan yaitu menjadi coklat tua. Di dalam sari buah, terdapat kandungan karbohidrat dimana salah satu pemecahan dari karbohidrat adalah sukrosa. Menurut
Winarno ${ }^{(5)}$, jika sukrosa dipanaskan terus sampai titik leburnya yaitu $160^{\circ} \mathrm{C}$ maka akan terjadi proses karamelisasi. Reaksi yang terjadi merupakan non-enzimatis yaitu reaksi karamelisasi yang menyebabkan permen menjadi gelap. Proses tersebut adalah setiap molekul sukrosa dipecah menjadi glukosa dan fruktosa, dimana suhu tinggi mampu mengeluarkan molekul air dari molekul gula, sehingga terbentuk glukosan dan fruktosan (dehidrasi). Setelah proses pemecahan dan dehidrasi adalah reaksi polimerisasi yaitu terbentuknya komponen polimer yang berwarna, menyebabkan larutan berwarna gelap.

Tabel 1. Pengaruh penambahan sari buah mangga kuwini hasil pengujian organoleptik terhadap tingkat warna, bau/aroma, tekstur dan rasa

\begin{tabular}{ccccc}
\hline & \multicolumn{4}{c}{ Nilai Uji Organoleptik } \\
\cline { 2 - 5 } & Warna & Bau & Tekstur & Rasa \\
\hline$M_{0}$ & $4,7^{\mathrm{c}}$ & 3,70 & 4,33 & 3,45 \\
$\mathrm{M}_{20}$ & $4,42^{\mathrm{bc}}$ & 4,54 & 4,33 & 4,12 \\
$\mathrm{M}_{25}$ & $4,29^{\mathrm{bc}}$ & 4,42 & 4,18 & 3,99 \\
$\mathrm{M}_{30}$ & $3,83^{\mathrm{ab}}$ & 4,50 & 3,66 & 4,55 \\
$\mathrm{M}_{35}$ & $3,54^{\mathrm{a}}$ & 4,50 & 3,54 & 4,49 \\
\hline
\end{tabular}

Keterangan:

$\mathrm{M} 0=$ mangga $0 \%, \mathrm{M} 20$ = mangga $20 \%$, M25 = mangga $25 \%$, M35= mangga $35 \%$

Nilai kesukaan: 1 = sangat tidak suka, $2=$ tidak suka, $3=$ cukup suka, $4=$ suka dan $5=$ sangat suka

Nilai tingkat kesukaan bau permen pada perlakuan penambahan sari buah mangga kuwini yaitu berkisar 3,70-4,54 (suka-sangat suka). Hasil analisis varians perlakuan penambahan sari buah mangga tidak memberikan pengaruh yang nyata pada tingkat kesukaan panelis terhadap bau permen. Bau suatu produk sangat berpengaruh terhadap selera konsumen yang berkaitan dengan indera penciuman sehingga menimbulkan keinginan untuk mengkonsumsi. Bau yang enak akan menggugah selera, sedangkan bau yang tidak enak akan menurunkan selera konsumen untuk mengkonsumsi produk tersebut $^{(18)}$. Nilai tingkat kesukaan terhadap bau dari permen pada Tabel 1, dapat dilihat bahwa cenderung meningkat degan makin bertambahnya konsentrasi penambahan sari buah mangga kuwini, karena mangga kuwini mempunyai bau khas tersendiri apabila dibandingkan dengan buah lainnya.

Tingkat kesukaan panelis terhadap tekstur dari permen menunjukkan bahwa pada perlakuan tanpa penambahan sari buah mangga (M0) mempunyai tingkat 
kesukaan paling tinggi yaitu dengan nilai rata-rata 4,33 dalam penilaian sangat suka.

Nilai rata-rata tingkat kesukaan tekstur permen pada penambahan sari buah mangga kuwini berkisar 3,54-4.3.3 (suka) pada Tabel 1. Hasil analisis varians perlakuan penambahan sari buah mangga tidak memberikan pengaruh nyata pada tingkat kesukaan tekstur permen. Pada perlakuan penambahan sari buah mangga dengan persentasi sampai $35 \%$ nilai tingkat kesukaan makin menurun.

Pembentukan tekstur produk selain dipengaruhi oleh komposisi sirup glukosa dan sukrosa juga dipengaruhi oleh penambahan sari buah pada produk permen tersebut. Sirup glukosa berpengaruh untuk memperbaiki tekstur dan memiliki sifat higroskopis yang rendah sehingga dapat digunakan sebagai pelindung pada permen. Sukrosa juga berfungsi sebagai pembentuk tekstur dan peningkatan kadar sukrosa yang akan meningkatkan kekentalan.

$$
\text { Menurut Ward dan Court }{ }^{(19)} \text {. }
$$

Campuran glukosa dalam permen dapat membuat tekstur yang dihasilkan lebih liat dan kekerasannya cenderung menurun. Hal inilah yang menyebabkan permen akan lebih sulit saat dicetak sesuai bentuk yang diinginkan, sehingga konsumen tidak menyukainya.

Rata-rata penilaian terhadap tingkat kesukaan rasa permen pada penambahan sari buah mangga kuwini berkisar 3,45-4,55. Hasil analisis varians perlakuan penambahan sari buah mangga tidak memberikan perbedaan tingkat kesukaan terhadap rasa. Dengan penambahan sari buah mangga kuwini rata-rata tingkat kesukaan makin tinggi.

\section{KESIMPULAN}

Semakin banyak penambahan sari buah mangga kuwini semakin menurun kadar sukrosa permen. Penambahan kosentrasi sari buah mangga kuwini pada permen keras dapat memenuhi syarat mutu SNI 3547.1:2008 untuk parameter kadar air, kadar sukrosa, kadar gula reduksi dan kadar abu. Secara organoleptik warna, bau, tekstur dan rasa dari permen disukai panelis.

\section{DAFTAR PUSTAKA}

1. Amos PW. Hard candy dengan flavor dari minyak pala. Jurnal Sains dan Teknologi Vol. 4 No. 5. BPPT. Jakarta. 2002.

2. Iriani ES, Said EG, Suryani A dan Setyadjid. Pengaruh konsentrasi penambahan pektinase dan kondisi inkubasi terhadap rendemen dan mutu jus mangga kuini (Mangifera odorata Griff.). Jurnal Pascapanen 2(1):11-17. 2005.

3. Prissilia $P$. Kualitas selai mangga kweni (Mangifera odorata Griff.) rendah kalori dengan variasi rebaudiosida A. Skripsi Fakultas Teknobiologi. Universitas Atma Jaya Yogyakarta. Yogyakarta. 2014.

4. Badan Standardisasi Nasional. SNI 3541.12008.Kembang Gula Keras; 2008.

5. Winarno FG. Kimia Pangan dan Gizi. PT. Gramedia. Jakarta. 2008.

6. Wahyuni HD. Mempelajari pembuatan hard candy dari gula invert sebagai alternatif pengganti sirup glukosa (Skripsi). Fateta, IPB. 1998.

7. Winarno FG. Kimia Pangan dan Gizi. Gramedia Pustaka Utama, Jakarta. 2004.

8. Jackson EB.. Sugar Confectionery Manufacture. London: Blackie Academic and Profesional. 1995.

9. Kusumawati RP. Pengaruh penambahan asam sitrat dan pewarna alami kayu secang (Caesalpinia sappan L) terhadap stabilitas warna sari buah belimbing manis (Averrhoa carambola L). Skripsi. IPB, Bogor. 2008.

10. Buckle $K A$, Edwards RA, Fleet $G H$ and Wootton $\mathrm{M}$. IImu Pangan. Penerjemah $\mathrm{H}$. Purnomo dan Adiono. Ul-Press. Jakarta. 2009.

11. Sularjo. Pengaruh perbandingan gula pasir dan daging buah terhadap kualitas permen pepaya. Magistra; 2010. 74:39-48.

12. Ashurts PR. Food Flavoring (Ed.). New York: The AVI Publ. 1991. 
13. Deman, John. Kimia Makanan. ITB : Bandung. 1997.

14. Wahyuni R. Optimasi pengolahan kembang gula jelly campuran kulit dan daging buah naga super merah (Hylocereus costaricensis) dan prakiraan biaya produksi. Universitas Brawijaya. Malang. 2010.

15. Nurwati. Formulasi hard candy dengan penambahan ekstrak buah pedada (Sonneratia caseolaris) sebagai flavor. Skripsi. Institut Pertanian Bogor. Bogor. 2011.
16. Wahyuni HD. Mempelajari pembuatan hard candy dari gula invert sebagai alternatif pengganti sirup glukosa. Jurusan Teknologi Pangan dan Gizi. Fakultas Teknologi Pertanian. Institut Pertanian Bogor. Bogor. 1998.

17. Sudarmadji S. Analisa Bahan Makanan dan Pertanian. Liberty Yogyakarta. Yogyakarta. 2010.

18. Ward and Courts. The Science of Technology of Gelatin. Academic Press. London. 1977. 